\title{
LA-5573-MS
}

Informal Report

Development of a Mobile Rock-Melting Subterrene Field Unit for Universal Extruding Penetrators 
This report was prepared as an account of work sponsored by the United States Government. Neither the United States nor the United States Atomic Energy Commission, nor any of their employees, nor any of their contractors, subcontractors, or their employees, makes any warranty, express or implied, or assum $\Rightarrow$ any legal liability or responsibility for the accuracy, completeness or usefulness oi any information, apparatus, product or process disclosed, or represents that its use vould not infringe privately owned rights.

In the interest of prompt distribution, this LAMS report was not edited by the Technical Information staff.

Printed in the United States of America. Available from National Technical Information Service

U.S. Department of Commerce

5285 Port Royal Road

Springfield, Virginia 22151

Price: Printed Copy $\$ 4.00$ Microtiche $\$ 1.45$ 
LA-5573-MS

Informal Report

UC-38

Reporting Date: March 1974 Issued: April 1974

$\pm$

los Nalamos

scientifle laboratory

of the University of California

LOS ALAMOS, NEW MEXICO 87544

1

\section{Development of a Mobile Rock-Melting Subterrene Field Unit for Universal Extruding Penetrators}

by

J. E. Griggs

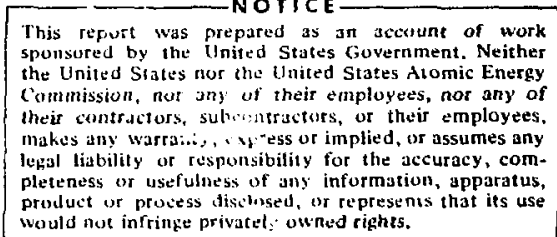

Work supported in part by a grant from the National Science Foundation, Research Applied to National Needs (RANN). 
DEVELOPMENT OF A MOBILE ROCK-MELTING

SUBTERRENE FIELD UNIT FOR UNIVERSAL EXTRUDING PENETRATORS

by

J. E. Griggs

ABSTRACT

A mobije rock-melting unit has been developed for field demonstration and testing of universal extmiding penetrators. The design, features, component functions, and operating data for this unit are described.

\section{INTRODUCTION}

Rock-melting penetrators are under development at the Los Alamos Scientific Laboratory (LASL) to pierce rock and soil by progressive melting rather than by chipping, abrading, or spalling. 1 This new technology, when perfected, will offer the possibility for desirable advancements in excavation and tunneling, and thus permit a more efficient utilization of the earth's resources.

The concept of rock melting offers more than just a new method of breaking or disintegrating rock - it simultaneously provides, in a single system, the three major elements of conventional excavation processes:

- Making the hole or tunnel,

- Supporting the wall, and

- Removing the debris.

The liquid form of the rock melt produced by the heated penetrator is the new element that provides for innovative solutions in these three areas. The melt can be formed into a glass lining to seal the walls of the hole or tunnel. In addition, exc ss liquid melt can be frozen either into glass rods, pellets, rock wool, or glass-cased cores for convenient remova). Thus, the rock-melting technique offers the potential of a complete system approach to the process of excavation.
The development program has concentrated on the design and development of a sequence of prototype electrically heated penetrators. An essential part of this development program is the field testing of the devices that have been developed successfully by testing in the laboratory. The objectives of field-testing complete penetrator systems are to evaluate the performance of the system under field conditions, to obtain more extended-1ife evaluations, and to demonstrate the feasibility of the rock-melting concept in situations that approach actual practice. Data and experience from field tests are fed back to optimize the design of the penetrator system. Field tests also denonstrate prototype system performance at nearly the level of development required for commercial applications, particularly with respect to equipment service life and reliability.

This report describes the design and construction of a mobile field demonstration and testing unit. This unit is designed to operate initially with the universal extruding penetrator (UEP) systems $^{2}$ developed $i_{1}$ the subterrene Program and is similar to that used for field testing of consolidating penetrators. 3 


\section{PURPOSE}

This mobile unit provides a means for demonstrating and field-testing universal extruding penetrators in high-density rocks. The unit produces vertical holes with a thin glass lining and removes the molten rock that remains after the glass lining has been formed.

Ariefly, the objectives and uses of this unit are:

- Provide the capability of in-situ tests in hard, dense rock so that operatis'g parameters can be established.

- Demonstrate the rock-melting and extruding principles and capabilities of a Subterrene.

- Serve as a prototype for basic design improvements in similar and advanced universal extruding penetrators.

\section{DESIGN REQUIREMENTS}

The unit must be mobile and capable of remotely controlled, self-contained operation. Because the unit is to be used for testing as well as demonstration, a data-acquisition system must be provided that will permit the detailed study of data in a systematic way rather than from sporadic entries in a simple logbook. A trailer, called the Instrumentation and Control trailer, is needed to house this system. And, because the penetrator requires the use of an inert gas (nitrogen) as a coolant and as a medium for transporting the extrudate to the surface, a nitrogen supply must also be provided.

Simplicity of operation and a minimum of operating personnel are other requirements. Two men should be able to erect the pulldown rig, to install the penetrator and stem assembly, and to proceed with the tests.

Commercially available components were used wherever possible to reduce costs (see Appendix A).

\section{SYSTEM DESCRIPTION}

\section{A. General Description}

A schematic of the completed mobile fielddenonstration and testing unit is presented in Fig. 1 ; field arrangements of the equipment are shown in Figs. I through 5.

Major components of this field demonstration and testing unit are:
- Pulldown rig,

- Hydraulic console and pump,

- Electric control unit and power supp'y,

- Nitrogen supply,

- Universal extruding penetrator and stem assembly.

The complete hydraulic system is composed of the first two of these components. The system is pictured in Fig. 2 and is shown schematically in Appendix B. All components, including the electric generator, are carried in the Instrumentation and Control (IC) trailer to the designated site, so that only the IC and nitrogen trailers are towed from one site to another. Upon arrival at a site and positioning of the IC and nitrogen trailers, the electric generator and the pulldown rig are unloaded and positioned for operation; hoses and cables are connected to the nitrogen trailer, to the electric generator, and to the pulldown rig; the penetrator and stem assembly is inserted in the pulldown rig and the rystem is readied for operation.

\section{B. Description of Components}

1. Pulldown Rig. This unit consists of a base structure weighted with lead bricks, sand bags, or other heavy objects; of four double-acting hydraulic cylinders; and of two mechanical, four-jawed

Instrumentation and control trailer (hydroulic pump and control, nitrogen control, power supply and controll)

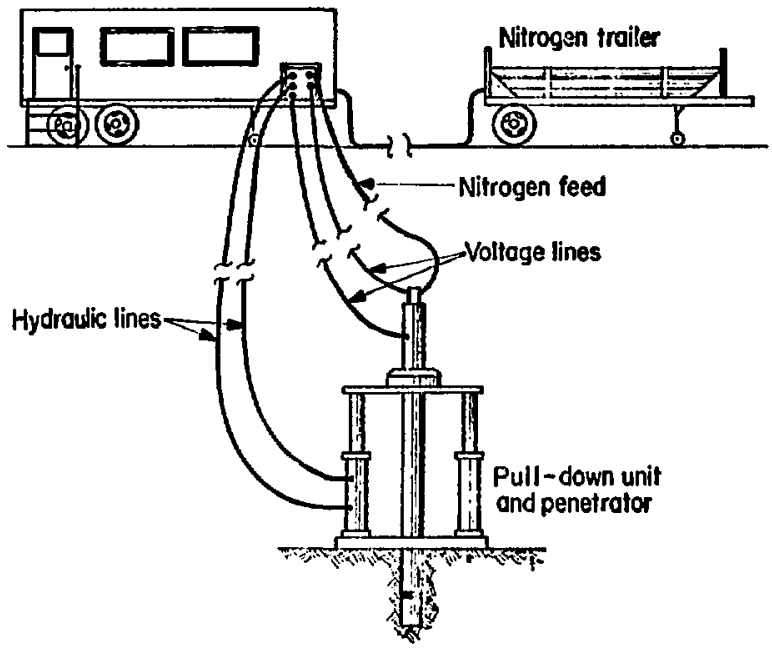

Fig. 1. Schematic of mobile field-demonstration and testing unit. 


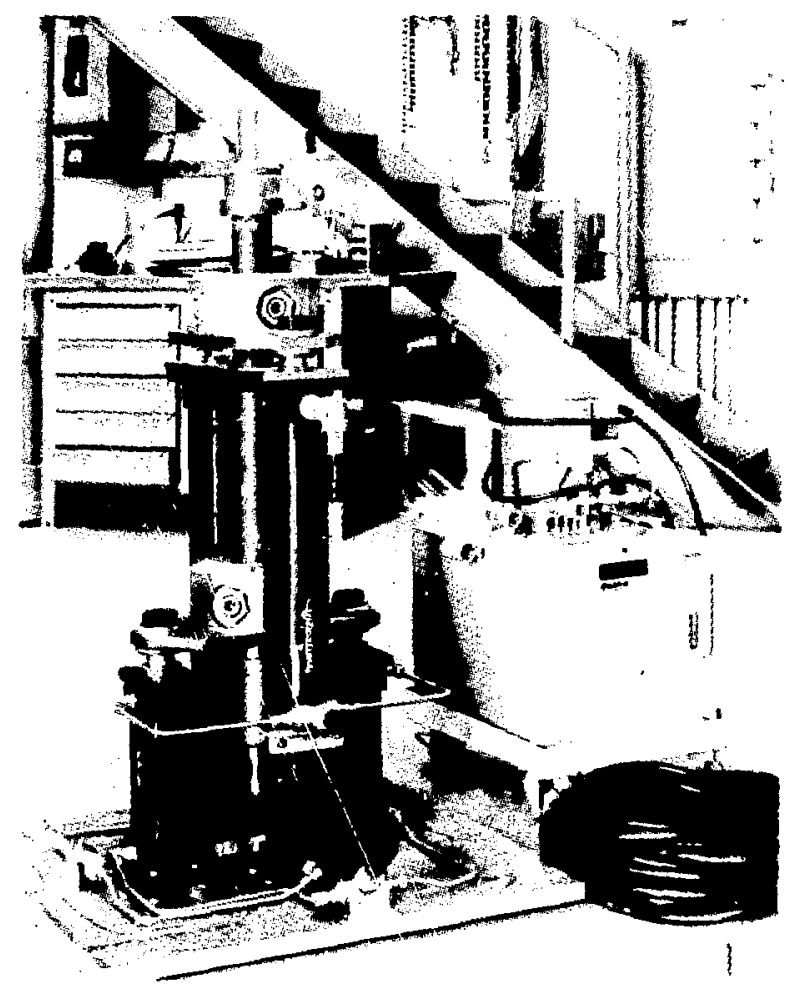

Fig. 2. Hydraulic unit.

chucks. Hydraulic pressure on the cylinders produces the force for pushing the hot penetrator into the rock and for extracting the penetrator. Two sets of hydraulic cylinders are used to ensure

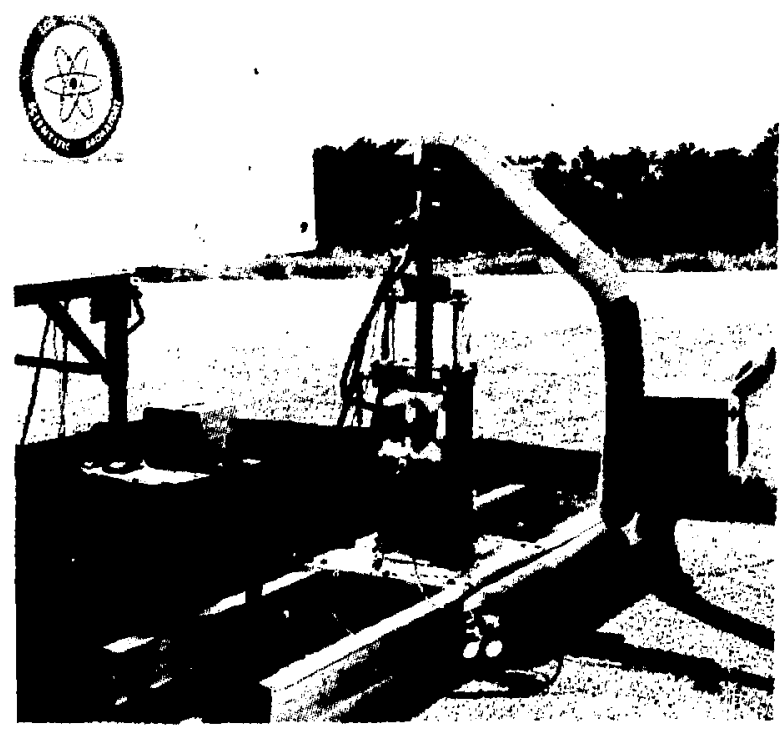

Fig. 3. Universal extruder demonstration assembly.

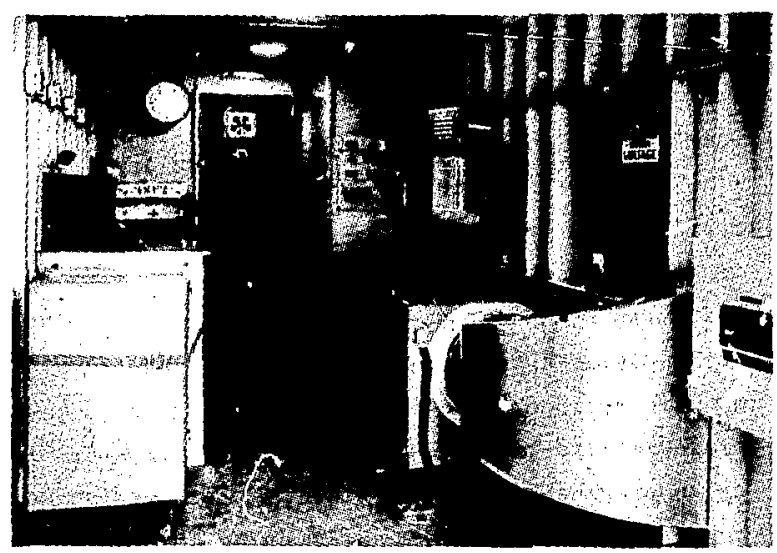

Fig. 4. Interior of instrumentation and control trailer.

continuous motion of the penetrator. As the longstroke $(600-\mathrm{mm})$ cylinders approach the end of their trave1, the short-stro'e $(150-\mathrm{mm})$ cylinders are actuated in the direction the 600-mm-stroke cylinders are moving, and are gripped to the penetrator stem. The 600-mm-stroke cylinders are freed from the stem and their direction is reversed so that they travel to a full-up position; at this point their direction is reversed again, they are gripped to the penetrator ster, and the 150-nm-stroke cylinders are freed from the stem and returned to their full-up position. As the 600-mm-stroke cylinders approach the end of their travel, the cycle is repeated. A hydraulic pressure of $2.75 \mathrm{MPa}$ (400 psig) produces either a downward force of $8.9 \mathrm{kN}(2000 \mathrm{lbf})$ on the advancing penetrator, or an upward force of $17.8 \mathrm{kN}$ (4000 lbf) for extracting the penetrator.

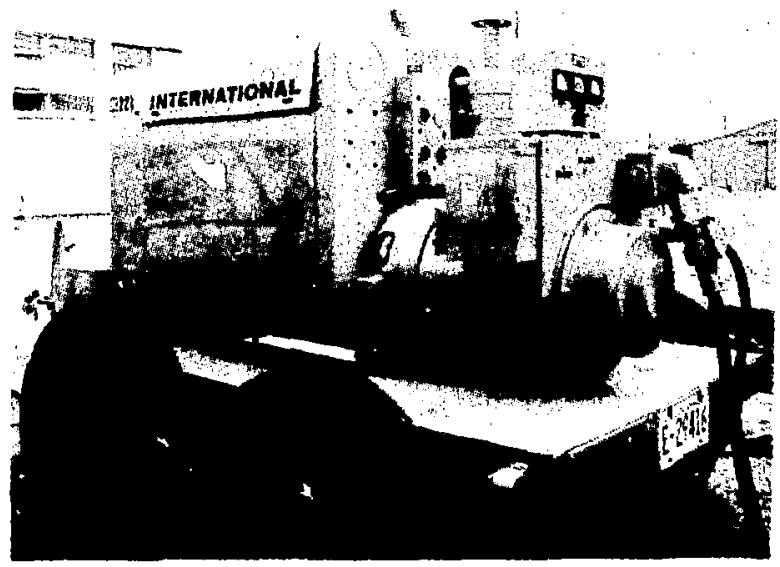

Fig. 5. 30-kw electric generator. 
2. Hydraulic Console and Pump. These componerits provide both directional control of the four hydraulic cylinders and the pressure to activate the cylinders.

The hydraulic consoie comprises a pressureregulating valve, two three-way valves fo: controlling the up or down motion on the two sets of hydraulic cylinders, an accumulator control valve for applying surge pressure to either set of hydraulic cylinders, a gage for observing accumulator pressure, and two gages for observing the hydraulic cylinder pressures (from which an operator can determine the amount of force being applied to the penetrator).

The purm provides a flow of pressurized hydraulic oil to the console for operating the penetrator pulldown unit and recharging the accumulator. This pressure may be adjusted up to $5.5 \mathrm{MPa}$ ( 800 psig). The pump is powered by a $1.12-\mathrm{kW}$ (1.5-hp) electric motor and preduces a flow of $0.17 \mathrm{\ell} / \mathrm{s}(2.7 \mathrm{gpm})$.

3. Electric Control Unit and Power Supply. These units provide for cortrolled supply of dc electric power to the heater in the penetrator. They consist of:

- A de power supply with an output capability of $1000 \mathrm{~A}$ and $40 \mathrm{~V}$.

- An electrical orierload-protection circuit.

- A chart recorder to record current and voltage.

- A tape printer that prints current, voltage, heater resistance, and kilowatts of power.

- A digital display that indicates current, voltage, heater resistance, and kilowatts of power.

- is 30-kW gasoline-engine-driven electrical generator which produces either three-phase, 60 -cycle power of $440 \mathrm{~V}$ and $220 \mathrm{~V}$, or onephase, 60-cycle power of $110 \mathrm{~V}$.

The interior of the trailer which houses these units, except the generator, is shown in Fig. 4. The generator is shown in Fig. 5.

4. Nitrogen Supply. Nitrogen is supplied to the penetrator and stem assembly through an inlet port in the uppermost section of the stem (Fig. 6), The gas flows in the annular region formed by the inner and outer stem and is used to cool the stem assembly and to solidify and transport the molten rock up the inner stem to the earth's surface.

A pressure-regulating valve and a rotameter are used to control the flow of nitrogen to the penetrator.

\section{Universal Extruding Penetrator and Stem} Assembly. Extrusion penetrators are required in dense materials and are constructed to remove the debris from the bore hole. The material is logically removed in three stages as shown in Fig. 6.

$$
\text { a. Stage } 1 \text { - Melting. Ideally, only the }
$$
material in the path of the penetrator needs raising to melting temperatures, as illustrated in
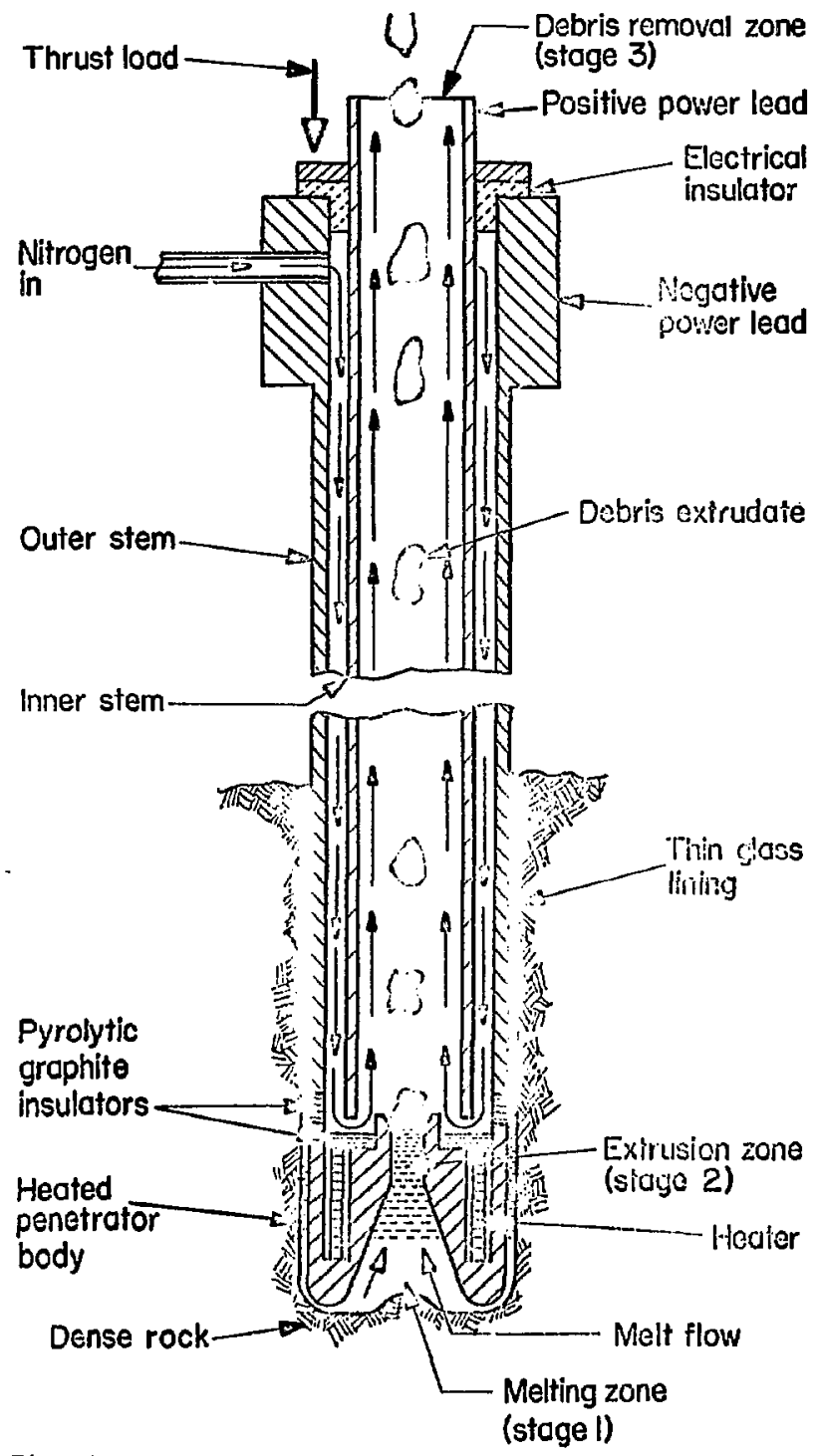

Fig. 6. Universal extruding penetrator and stem assembly. 
Fig. 6, but peripheral heating along the penetrator can be utilized as desired to provide a glass lining.

b. Stage 2 - Melt Extrusion. If the penetrator is to advance, the melted material must be transported out of the hole. This is achieved by extrusion, i.e., by applying a thrust load to the melting penetrator and displacing the melt by pressure. The melt, confined by the unmelted rock and the hot melting face of the penetrator, is ducted to a hole (or holes) in the melting face and is thus extruded.

\section{c. Stage 3 - Transport of Solid Material.}

The material is chilled and freezes shortly after the cooling fluid impinges upon the extrudate exiting from the extrusion region. If frozen quickly, the material will be in the form of glass rods, pellets, or rock wool. The flowing coolant can then easily transport these small pieces up the stem and through the exhaust section.

\section{v. OPERATION OF UNIT}

A. Power and Coolant Requirements

The Universal Extruding Penetrator for which this equipment has been developed was laboratorytested for many hours, and the parameters from those tests were used in operating the mobile rockmelting Subterrene field unit.

The power display unit used in the mobile field unit is identical to that used in laboratory tests, so that the electric-power parameters can be monitored without conversion.

The nitrogen-supply pressure gages and flow meters had also been used in the laboratory and therefore required no conversions; and the hydraulic pulldown rig wa: calibrated to match the hydraulic loading system of the laborator. B. Required Monitoring During Operation

The following quantities must be monitored to properly operate the mobile field unit with a 66mm-diam Universal Extruding Penetrator:

- Power input to the heater must remain below a specified level to prevent damage to the heater but must be high enough to maintain melting;

- Resistance of the heater element;

- Inlet pressure of the cooling and extrudateejecting nitrogen gas;
- Hydraulic pressure on the thruster cylinders; and

- Rate of penetration.

Heater resistance and power input are important parameters in operating the mobile field unit. The graphite heater is built into the penetrator. This heater has a negative coefficient of resistance, i.e., its resistance decreases with increasing temperature. With increasing temperature an unstable situation may thus be created, with the result that the carbon heater elements may be damaged by overheating. The operator must therefore monitor heater resistance and must reduce power if the resistance falls below a specified level. The digital powerdisplay unit in the IC trailer provides the necessary control capability.

The hydraulic pressure is read directly from gages, is easily monitored, and is controlled by valves on the hydraulic console. The $\mathrm{N}_{2}$ pressure is controlled by a throttling valve on the $\mathrm{N}_{2}$ control panel and is monitored by both a flow meter on the panel and a gage at the top of the pipe stem.

The rate of penetration is measured by timing the movement of the hydraulic pistons in the thruster by means of a linear potentiometer on the thruster and a stopwatch..

\section{Typical Operating Parameters}

Typical data for the mobile field unit after initial warmup are shown in Table $I$.

Power and $\mathrm{N}_{2}$ pressure are increased according to calculated values with increasing depth of penetration to compensate for decreasing power and pres. sure in the pipe stem.

\section{CONCLUSIONS}

The Field Demonstration Unit has produced glasslined holes in basalt and can handle extruding penetrators up to $82 \mathrm{mn}$ in diameter. The controls are sufficient to operate the system with ease. The convenient arrangement of gages, instruments, and levers permits one person to monitor and operate the unit during downward movement of the thruster. A second person is requiced for adding additional pipe to the stem, for regripping the pipe at the end of each downward stroke, and for occasionally checking the compressor and electrical power supply for proper operation and adequacy of fuel reserves. 
TABLE I

TYPICAL OPERATING DATA FOR MOSILE FIELD UNIT

\begin{tabular}{ll}
\hline Rock formation & Basalt \\
dc voltage to stem, $V$. & 28.3 \\
dc current, $A$ & 210 \\
Power input, $\mathrm{kW}$ & 5.94 \\
System resistance, $\Omega$ & 0.135 \\
Thruster load, $\mathrm{kN}\left(1 \mathrm{~b}_{f}\right)$ & $6.68(1500)$ \\
$\mathrm{N}_{2}$ flow rate, $\mathrm{kg} / \mathrm{s}(\mathrm{scfm})$ & $0.025(45.5)$ \\
Advance rate, $\mathrm{mm} / \mathrm{s}(\mathrm{in} . / \mathrm{min})$ & $0.07(0.175)$
\end{tabular}

REFERENCES

1. R. J. Hanold, "Rapid Excavation by Rock Melting - LASL Subterrene Program, "Los Alamos Scientific Laboratory Status Report LA-5459-SR (November 1973).

2. J. W. Neudecker, A. J. Giger, P. E. Armstrong, "Design and Development of Prototype Universal Extruding Subterrene Penetrators," Los Alamos Scientific Laboratory Report LA-5205-MS (March 1973).

3. R. E. Willians, "Development and Construction of a Modularized Mobile Rock-Melting Subterrene Demonstration Unit," Los Alamos Scientific Laboratory Report LA-5209-MS (March 1973).

\section{APPENDIX A}

COST OF A MOBILE ROCK-MELTING SUBTERRENE FIELD UNIT

FOR UNIVERSAL EXTRUDING PENETRATORS

Most components of the Mobile Field Unit were commercially available and were either procured as complete units or, as in the case of the consoles, assembled from conmercially procured parts. The penetrator and the parts of the stem which connect to the penetrator are special components developed for the Subterrene program and were manufactured by commercially operated machine shops in accordance with LASL drawings. Some small mechanical items were, for convenience, manufactured by LASL although all could have been procured from commercial sources. The transistorized computer-and-display panel was designed and fabricated at LASL, but can be procured from a commercial electronics fabricator, either per LASL's design or the supplier's own design.

A cost breakdown of the Mobile Field Unit is given in Table A-I. 


\begin{tabular}{|c|c|c|}
\hline Component & \multicolumn{2}{|c|}{ Cost, $\$$} \\
\hline \multicolumn{3}{|l|}{ Thruster } \\
\hline Structure & & 1000 \\
\hline Hydraulic cylinders & & 560 \\
\hline Mechanical chuck & & 440 \\
\hline & Subtota 1 & 2000 \\
\hline \multicolumn{3}{|l|}{ Drill Stem, $13 \mathrm{~m}(40 \mathrm{ft})$} \\
\hline Drill rod & & 500 \\
\hline Internal pipes & & $\underline{1000}$ \\
\hline & Subtotal & 1500 \\
\hline Hydraulic Console, Pumps, Valves, etc. & & 2000 \\
\hline $\mathrm{N}_{2}$ Control Panel & & 400 \\
\hline $\mathrm{N}_{2}$ Tank Trailer & & 750 \\
\hline & Subtotal & 3150 \\
\hline \multicolumn{3}{|l|}{ Electric Power Supply } \\
\hline Generator, $30 \mathrm{~kW}$ ac & & 3850 \\
\hline Power cables & & 1000 \\
\hline & Subtotal & 4850 \\
\hline \multicolumn{3}{|l|}{ Control Console and Power Display Unit } \\
\hline Control console & & 1600 \\
\hline \multirow[t]{2}{*}{ Power display unit } & & 3500 \\
\hline & Subtotal & 5100 \\
\hline Trailer & TOTAL & $\overline{10000^{*}}$ \\
\hline Penetrators (3) & & 2400 \\
\hline Miscellaneous items & & $\underline{1000}$ \\
\hline & Subtotal & 3400 \\
\hline & TOTAL & 30000 \\
\hline
\end{tabular}

\footnotetext{
This item was procured from government surplus at no cost to the
} project. The value shown is an approximate replacement cost. 


\section{APPENDIX B}

SCHEMATIC DRAWING OF HYDRAULIC SYSTEM

The components of the hydraulic system, indicated in Fig. B-1, consist of the pump assembly, the hydraulic console, and the double pulldown rig. The hydraulic system provides the force to push the heated penetrator into the rock and to withdraw it when necessary. The gages and valves on the console allow the operator to monitor and to control the forces required for these operations.

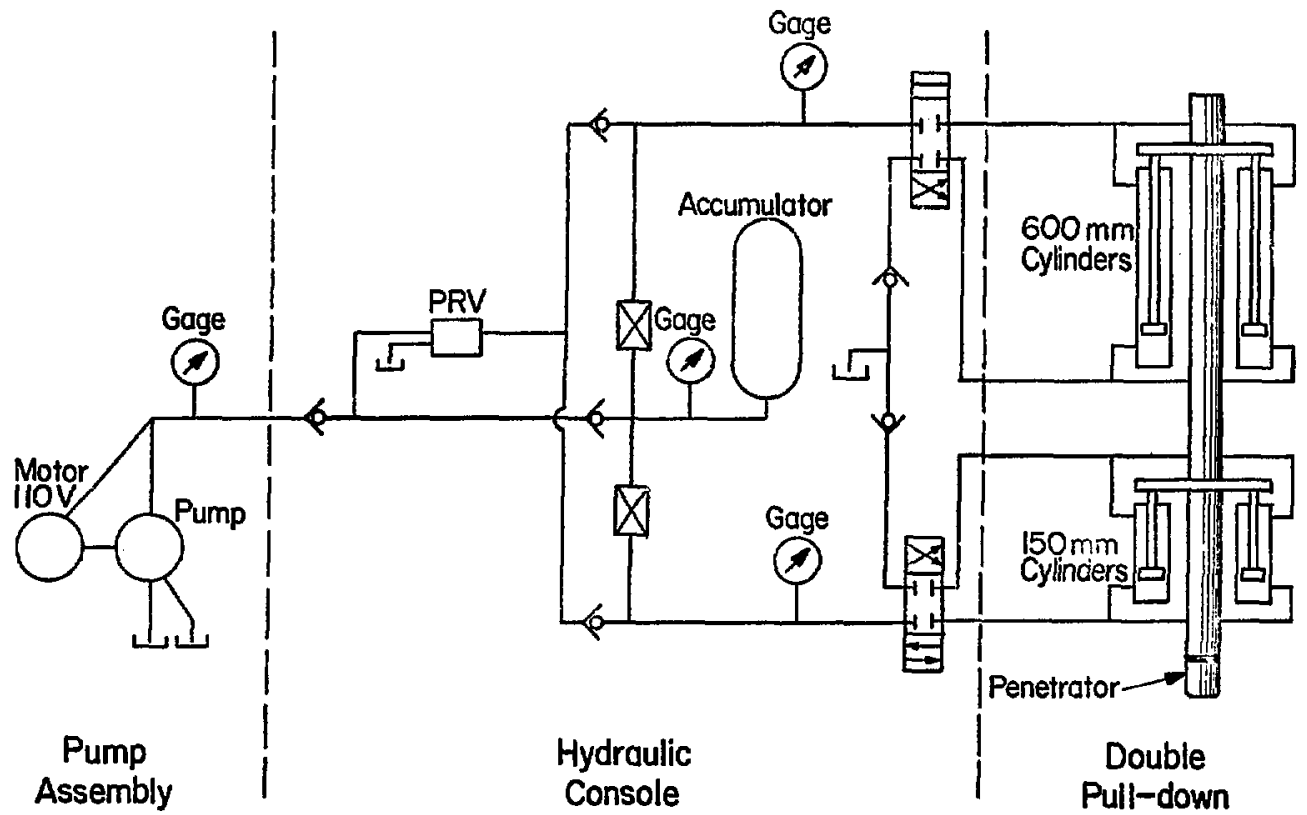

Fig. B-1. Schematic of hydraulic system. 